\title{
A pilot study evaluating erect chest imaging in children, using the Lodox Statscan digital $X$-ray machine
}

\author{
Rupesh Baloo Daya, $M B$ BCh \\ Maurice A Kibel, FRCP (Edin), DCH (RCP\&S, \\ Lond) \\ School of Child and Adolescent Health, Institute of Infectious Diseases and \\ Molecular Medicine, University of Cape Town \\ Richard Denys Pitcher, MB ChB, FCRad (D) SA \\ Department of Paediatric Radiology, School of Child and Adolescent Health, \\ Red Cross War Memorial Children's Hospital, and University of Cape Town \\ Lesley Workman, RN \\ South African Tuberculosis Vaccine Initiative, Institute of Infectious Diseases \\ and Molecular Medicine, University of Cape Town \\ Tania S Douglas, PhD \\ Virginia Sanders, MSC \\ Medical Imaging Research Unit, Department of Human Biology, University of \\ Cape Town
}

\section{Abstract}

Background. Chest radiography accounts for a significant proportion of ionising radiation in children. The radiation dose of radiographs performed on the Lodox Statscan system has been shown to be lower than that of a computed radiography (CR) system. The role of the Lodox Statscan (subsequently referred to as the Statscan) in routine erect chest radiography in children has not been evaluated.

Objective. To evaluate the image quality and diagnostic accuracy of erect paediatric chest radiographs obtained with the Statscan and to compare these with conventional erect chest images obtained with a CR system.

Materials and methods. Thirty-three children with suspected chest pathology were enrolled randomly over a period of 3 months. Erect chest radiographs were obtained with the Statscan and a Shimadzu R-20J X-ray machine coupled with a Fuji FCR 5000 CR system. Image quality and diagnostic accuracy and diagnostic capability of the two modalities were evaluated and compared.

Results. The erect Statscan allowed superior visualisation of the 3 major airways. Statscan images, however, demonstrated exposure and movement artifacts, with hemidiaphragms and ribs most prone to movement. Bronchovascular clarity was also considered unsatisfactory on Statscan images.

Conclusion. The Statscan has limitations in erect chest radiography in terms of movement artefacts, exposure fluctuations, and poor definition of lung markings. Despite this, the Statscan allows better visualisation of the major airways, equivalent to a 'high $\mathrm{kV}$ ' film, at a fraction of the radiation dose, which supports the finding of an earlier study evaluating Statscan images in trauma cases, where the images were taken supine. The Statscan has great potential in assisting in the diagnosis of child- hood tuberculosis where airway narrowing occurs as a result of nodal compression.

\section{Introduction}

Ionising radiation is potentially harmful to humans, with a tendency to induce malignancy in tissue. ${ }^{1,2}$ Routine chest radiography is the most frequent radiological examination performed worldwide on both adults and children, ${ }^{3}$ accounting for a significant proportion of ionising radiation attributable to diagnostic imaging. ${ }^{1,4}$ A reduction in the radiation dose of a chest radiograph would therefore have significant advantages for both public health and individual radiation risk; ${ }^{5}$ this is particularly true in paediatric practice, given the increased risk of radiation-induced malignancy in children. ${ }^{1,2}$

A study conducted at Red Cross War Memorial Children's Hospital $(\mathrm{RCH})$ showed that the radiation dose of a paediatric chest radiograph performed on the Statscan digital radiography unit (Lodox Systems Pty Ltd, Sandton, South Africa) is lower than that of conventional X-ray equipment coupled with a computed radiography (CR) system. ${ }^{6}$ The Statscan has been shown to provide lower doses than CR for other anatomical areas in paediatric patients, ${ }^{6}$ and than conventional radiography systems for adult patients. ${ }^{7}$ The utility of the Statscan in the trauma setting has been demonstrated. ${ }^{8-10}$

In a study on triage evaluation of polytrauma patients, the Statscan afforded superior visualisation of the paediatric trachea and main bronchi on AP supine chest radiographs, compared with CR. ${ }^{11}$ However, the former's role in routine erect chest radiography in children has not been evaluated. As routine chest radiographs are performed erect, a pilot study was conducted to assess the image quality and diagnostic accuracy and capabilities of erect paediatric chest radiographs obtained with the Statscan, compared with erect chest radiographs obtained with conventional X-ray equipment combined with a CR system.

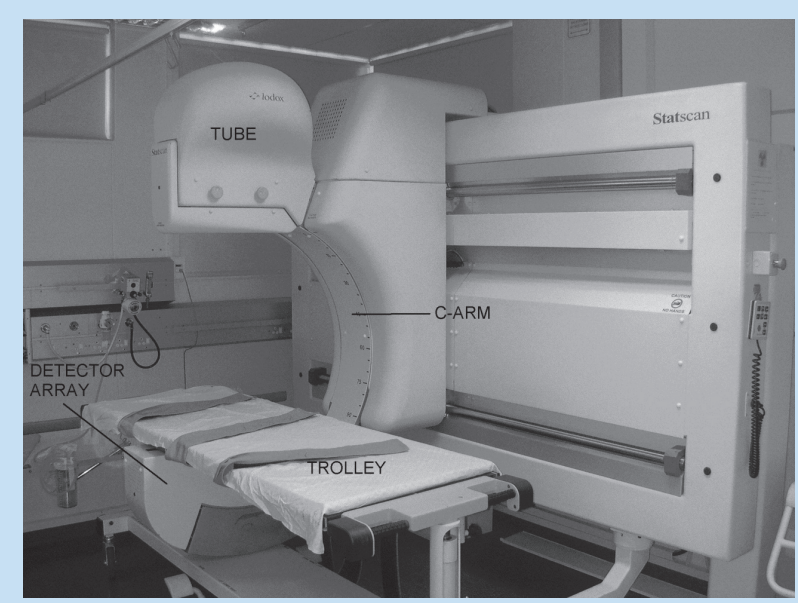

Fig.1. The Statscan machine and its main components. 


\section{ORIGINAL ARTICLE}

\section{Materials}

\section{Lodox Statscan}

The Statscan machine, approved by the Food and Drug Administration (FDA) in the United States, uses linear slot scanning technology. It comprises a slotted tungsten plate over the X-ray tube, providing collimated fan-beam radiation, aligned on a $\mathrm{C}$-arm opposite a detector array of 580060 -micron scintillator elements which are optically linked to charge-coupled devices (CCDs). ${ }^{6,11,12}$ When the Statscan is used for polytrauma imaging (for which it was designed), the patient is supine on a horizontal custom-built trolley that 'docks' onto the C-arm (Fig. 1). Scanning is in a cranio-caudal direction, producing an adult AP bodygram in approximately 13 seconds. For erect chest radiography, the Carm is rotated 90 degrees anti-clockwise and a custom-built chair positioned at the foot of the X-ray table, thus facilitating erect projections of the paediatric chest. Scanning is from right to left for the AP study, and anterior-to-posterior for the lateral view. Scan times were approximately 3 - 4 seconds, depending on the size of the child. Exposure factors were similar to those previously documented for Statscan radiation dose measurements. ${ }^{6}$

\section{Conventional X-ray machine coupled with a CR system}

A Shimadzu R-20J X-ray machine (Shimadzu Corporation, Chiyoda-ku, Japan), coupled with a Fuji FCR 5000 CR system (Fuji Photo Film Co. Ltd, Tokyo, Japan) was used, employing standard paediatric exposure factors. ${ }^{6}$

\section{Methods}

After obtaining consent from departmental and institutional ethics committees, a pilot study was conducted over 3 months on a random cohort of 33 patients presenting with signs of chest pathology to the Emergency Unit of the RCH. Erect AP and lateral chest radiographs on both CR and Statscan systems were obtained for all participants, after obtaining informed consent from parents or legal guardians. The mean age of the children enrolled was 46.3 months (range 0.9 - 125.2). Twenty-four boys and 9 girls were included in the study.

Each pair of radiographs was assigned a random study number and printed on standard analog X-ray film after removal of patient details. Image pairs were independently evaluated for image quality, diagnostic accuracy and diagnostic capability by a paediatric radiologist and a paediatrician experienced in chest radiology. Evaluators were blinded to clinical details and the modality that had generated the image pair.

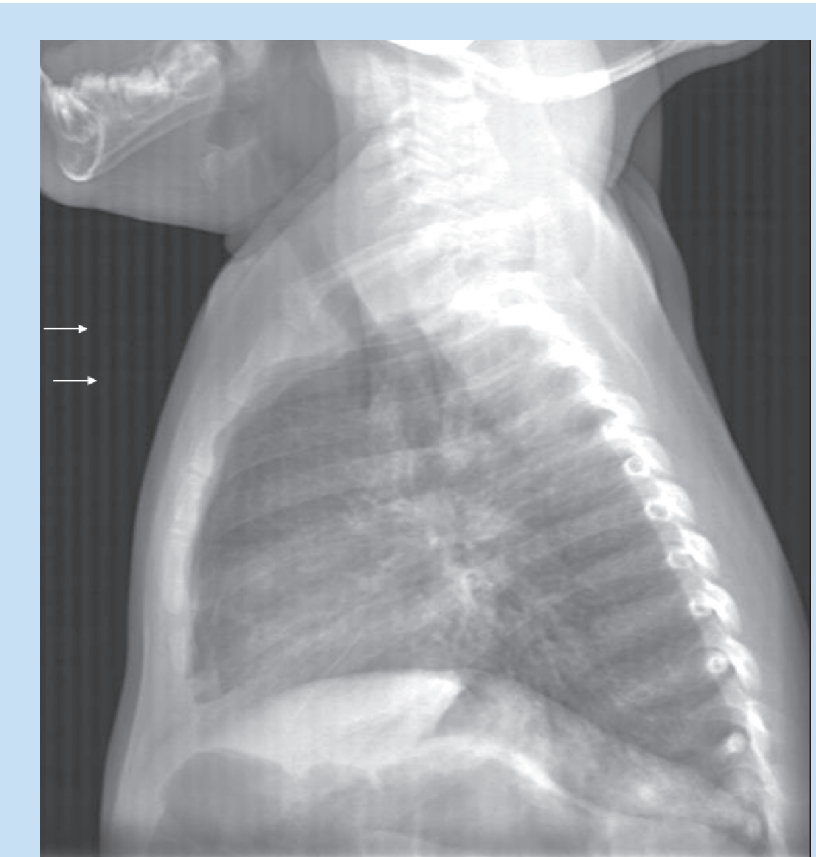

Fig. 2. Image showing the chevron artefact consisting of alternating dark and light bands, indicated by the white arrows.

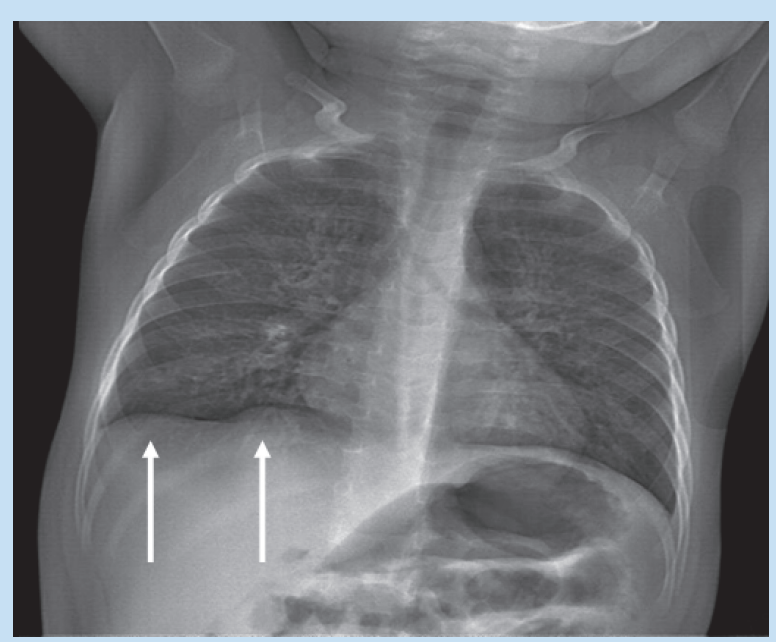

Fig. 3. Image showing the movement artefact involving the hemidiaphragm, indicated by the arrows.

Table I. Airway visualisation grading

$\begin{array}{lll}\text { Grade } & \text { Length of airway } & \text { Clarity of margins } \\ 0 & \text { No portion of airway seen. } & \text { Airway not visualised. } \\ 1 & \text { Not seen in entire length. } & \text { No portions showing well defined margins. } \\ 2 & \text { Seen in entire length } & \text { Segments showing well defined margins. } \\ 3 & & \text { Entire length of airway has well defined margin. }\end{array}$


Table II. Assessment of agreement between observers and modalities for visualisation of the airways, as judged by the airways index

\begin{tabular}{|c|c|c|c|c|c|c|c|}
\hline \multirow[b]{2}{*}{ Airways index } & \multirow{2}{*}{$\begin{array}{l}\text { Agreement } \\
(\%)\end{array}$} & \multirow{2}{*}{$\begin{array}{l}\text { Expected } \\
\text { agreement } \\
(\%)\end{array}$} & \multirow[b]{2}{*}{$K w$} & \multirow[b]{2}{*}{$p$} & & \multicolumn{2}{|c|}{ Score } \\
\hline & & & & & & Mean & Range \\
\hline \multicolumn{8}{|l|}{ Right main bronchus } \\
\hline \multirow{2}{*}{$\begin{array}{l}\text { Observer } 1 \text { on Statscan and } \\
\text { CR }\end{array}$} & \multirow{2}{*}{76.0} & \multirow{2}{*}{75.1} & \multirow{2}{*}{0.0380} & \multirow{2}{*}{0.2717} & $\begin{array}{l}\text { Observer } 1 \\
\text { Statscan }\end{array}$ & 4.8 & $0-5$ \\
\hline & & & & & $\begin{array}{l}\text { Observer } 2 \\
\text { Statscan }\end{array}$ & 3.8 & $2-5$ \\
\hline \multirow{2}{*}{$\begin{array}{l}\text { Observer } 2 \text { on Statscan and } \\
\text { CR }\end{array}$} & \multirow{2}{*}{60.9} & \multirow{2}{*}{61.9} & \multirow{2}{*}{-0.0256} & \multirow{2}{*}{0.6710} & $\begin{array}{l}\text { Observer } 1 \\
\text { CR }\end{array}$ & 3.8 & $0-5$ \\
\hline & & & & & $\begin{array}{l}\text { Observer } 2 \\
\text { CR }\end{array}$ & 2.3 & $0-4$ \\
\hline \multicolumn{8}{|l|}{ Left main bronchus } \\
\hline \multirow{2}{*}{$\begin{array}{l}\text { Observer } 1 \text { on Statscan and } \\
\text { CR }\end{array}$} & \multirow{2}{*}{70.9} & \multirow{2}{*}{67.6} & \multirow{2}{*}{0.0998} & \multirow{2}{*}{0.0698} & $\begin{array}{l}\text { Observer } 1 \\
\text { Statscan }\end{array}$ & 4.7 & $0-5$ \\
\hline & & & & & $\begin{array}{l}\text { Observer } 2 \\
\text { Statscan }\end{array}$ & 3.5 & $2-5$ \\
\hline \multirow{2}{*}{$\begin{array}{l}\text { Observer } 2 \text { on Statscan and } \\
\text { CR }\end{array}$} & \multirow{2}{*}{73.1} & \multirow{2}{*}{71.6} & \multirow{2}{*}{0.0523} & \multirow{2}{*}{0.1865} & $\begin{array}{l}\text { Observer } 1 \\
\text { CR }\end{array}$ & 3.5 & $0-5$ \\
\hline & & & & & $\begin{array}{l}\text { Observer } 2 \\
\text { CR }\end{array}$ & 2.2 & $0-4$ \\
\hline \multicolumn{8}{|l|}{ Trachea (antero-posterior) } \\
\hline \multirow{2}{*}{$\begin{array}{l}\text { Observer } 1 \text { on Statscan and } \\
\text { CR }\end{array}$} & \multirow{2}{*}{76.2} & \multirow{2}{*}{74.1} & \multirow{2}{*}{0.0799} & \multirow{2}{*}{0.0562} & $\begin{array}{l}\text { Observer } 1 \\
\text { Statscan }\end{array}$ & 4.9 & $3-5$ \\
\hline & & & & & $\begin{array}{l}\text { Observer } 2 \\
\text { Statscan }\end{array}$ & 4.0 & $2-5$ \\
\hline Observer 2 on Statscan and & 711 & 607 & 00450 & 02064 & $\begin{array}{l}\text { Observer } 1 \\
\text { CR }\end{array}$ & 4.2 & $2-5$ \\
\hline $\mathrm{CR}$ & 11.1 & 09.1 & 0.0432 & 0.2904 & $\begin{array}{l}\text { Observer } 2 \\
\text { CR }\end{array}$ & 3.1 & $0-5$ \\
\hline Trachea (lateral) & & & & & & & \\
\hline Observer 1 on Statscan and & 880 & 889 & $=0766$ & 07400 & $\begin{array}{l}\text { Observer } 1 \\
\text { Statscan }\end{array}$ & 4.92 & $4-5$ \\
\hline CR & 00.0 & 00.9 & -0.0700 & 0.1700 & $\begin{array}{l}\text { Observer } 2 \\
\text { Statscan }\end{array}$ & 3.68 & $2-5$ \\
\hline Observer 2 on Statscan and & 733 & 670 & 1009 & 00783 & $\begin{array}{l}\text { Observer } 1 \\
\text { CR }\end{array}$ & 4.68 & $1-5$ \\
\hline CR & 15.3 & 07.0 & 0.190 & 0.0103 & $\begin{array}{l}\text { Observer } 2 \\
\text { CR }\end{array}$ & 3.44 & $2-5$ \\
\hline
\end{tabular}

The following technical aspects were evaluated:

- Rotation. Scored as: present - 2, absent - 0, uncertain - 1 .

- Exposure. Scored as: satisfactory - 2, unsatisfactory - 0, uncertain -1 .

- Inspiratory excursion. Scored as: satisfactory - 2, unsatisfactory - 0 , uncertain -1 .

General image quality was assessed by evaluating each of the following for movement artefacts and resolution: vertebral column, clavicles, ribs, hemidiaphragms, trachea, main bronchi, heart, mediastinum and bronchovascular markings. Movement artefact was scored as: present
-2 , absent -0 , uncertain -1 , while resolution was scored as: satisfactory -2 , unsatisfactory -0 , uncertain -1 .

Proximal airway visualisation was evaluated according to the 'Airways Index' ( 0 - 5), i.e. the sum of the scores for length of airway visualised $(0-2)$ and the clarity of margins $(0-3),{ }^{11}$ as shown in Table I. The trachea and main bronchi were assessed.

Diagnostic capability was assessed by the ability of the two modalities to demonstrate the following pleural, mediastinal or pulmonary pathologies: (i) pneumothorax, (ii) pleural effusion, (iii) mediastinal adenopathy, (iv) consolidation, ( $v$ ) atelectasis, (vi) bronchial wall 
Table III. Percentage agreement for diagnostic capabilities between the two modalities

\begin{tabular}{|c|c|c|c|}
\hline Pathology & $\mathbf{C R}$ & Statscan & $\%$ agreement \\
\hline Normal & 3 & 2 & 66 \\
\hline Hyperinflated but clear lungs & 3 & 2 & 66 \\
\hline Hyperinflated lungs with peribronchial infiltrate & 9 & 6 & 66 \\
\hline Consolidation & 14 & 7 & 50 \\
\hline Mediastinal adenopathy & 2 & 2 & 100 \\
\hline Interstitial pattern (reticulo-nodular) & 2 & 0 & 0 \\
\hline Total & 33 & 19 & 58 \\
\hline
\end{tabular}

thickening, (vii) peribronchial infiltrates, (viii) pulmonary air cysts, (ix) pulmonary nodules, and $(x)$ an interstitial pulmonary pattern. These were recorded as present (2), absent (0) or uncertain (1).

Agreement between radiographic methods was assessed with the aid of Cohen's weighted kappa statistic $(K w) .{ }^{13} \mathrm{Kw}$ accounts for both percentage agreement and percentage agreement expected by chance, and weights disagreement according to its magnitude, making it suitable for ordinal data. Absolute error weights were used. The null hypothesis that agreement is due to chance was tested for $K w$ using the $p$ value at the $95 \%$ significance level. $K w$ is interpreted as follows: below $20 \%$ is regarded as poor; 21 - 40\% fair; 41 - 60\% moderate; 61 - 80\% good; and $>80 \%$ as very good. ${ }^{13}$

\section{Results}

\section{Technical evaluation}

\section{Longitudinal rotation}

There was no difference in the clinically significant rotation on AP projection between the Statscan and CR images. On the lateral Statscan images, longitudinal rotation was considered clinically significant in one instance (3\%). The lateral CR images showed clinically significant longitudinal rotation in 2 cases (6\%).

\section{Horizontal rotation}

There was no clinically significant horizontal rotation on the Statscan images. In 2 (6\%) of the CR images, horizontal rotation was considered clinically significant.

\section{Exposure factors}

Nine (27\%) of the Statscan images demonstrated exposure artefacts, manifesting as longitudinally orientated, alternating light and dark bands, extending across the image (Fig. 2). On 2 (6\%) images, the artefact involved only the AP projection. On 3 (9\%), it was manifest on the lateral projection alone, while in $4(12 \%)$, both AP and lateral projections were degraded. This was termed the 'chevron exposure artefact'. None of the CR images showed exposure artefacts.

\section{Inspiratory excursion}

The average and range of the number of posterior ribs visualised were similar on CR and Statscan, and for the different observers. More anterior ribs were visible on CR than on Statscan. In 18 cases, hyperinflation was diagnosed or suspected on the Statscan images, compared with 21 cases on the CR. Of note on the AP Statscan images was the potential for different degrees of inspiratory excursion to be demonstrated in the hemithoraces of the same patient (Fig. 3). The discussion elaborates on this point.

\section{Cardiothoracic ratio (CTR)}

CTR was measurable in 23 (69.6\%) of image pairs. In the remainder, chest pathology obscured the heart border. The mean CTR on the Statscan was $50.3 \mathrm{~mm}$ (range 40 - 58), compared with $50.0 \mathrm{~mm}$ (range 38 - 60) for CR.

\section{Image quality}

\section{Movement}

The hemidiaphragms and ribs were the structures most prone to movement on the Statscan images. In 4 (12\%) images, the AP projection showed such artefact involving either the left or right hemidiaphragm $(\mathrm{R}-3 ; \mathrm{L}-1)$, while this was seen on $5(15 \%)$ of the lateral projections. The ribs showed movement on $2(6 \%)$ of the AP and $1(3 \%)$ of the lateral Statscan projections. No movement artefacts were seen on CR images.

\section{Resolution}

Bronchovascular clarity was considered unsatisfactory on 9 (27\%) of the Statscan images, involving the AP projection in $5(15 \%)$ cases, the lateral projection in $7(21 \%)$, and both views in 3 (9\%) cases. Exposure or movement artefact could be implicated in all instances. In a further 6 $(18 \%)$, there was uncertainty about bronchovascular clarity.

\section{Visualisation of the major airways}

The Statscan allowed superior visualisation of the 3 major airways (Table II). The left main bronchus (LMB) was least well- and the trachea best-visualised. The Statscan afforded better visualisation of the right main bronchus (RMB) by an average of 1.8 points and the LMB by an average of 1.25 points. The disparity in image quality was not as great for tracheal visualisation, where the Statscan scored an average of 0.8 points better than $\mathrm{CR}$ on the AP projection and 0.24 points better on the lateral projection.

\section{Diagnostic capability}

The spectrum of chest pathology, with inter-modality diagnostic agreement, is shown in Table III. In 19 cases (58\%), there was diagnostic agreement between the modalities. This agreement was highest for mediastinal pathology (100\%) and least for diffuse interstitial pulmonary disease $(0 \%)$.

In 14 cases (42\%), the Statscan images had diagnostic limitations, with false negative findings in $12(86 \%)$ and false positive findings in 2 (14\%) cases. In the 12 false negative cases, the following technical fac- 
tors were implicated: $(i)$ chevron exposure artefact in 9 (64\%) of cases, occurring alone in 7 cases $(50 \%)$ and in combination with movement of the hemidiaphragms in 2 instances (14\%), (ii) movement artefact in $2(14 \%)$ of cases, and (iii) clinically significant vertical rotation in one (7\%) case.

\section{Discussion}

The protocol for chest radiography at our institution includes both $\mathrm{AP} / \mathrm{PA}$ and lateral projections, bearing in mind the high prevalence of pulmonary tuberculosis (PTB) in South Africa and the increased sensitivity of the lateral projection for diagnosis of PTB. ${ }^{14,15}$ The erect Statscan images were taken in the AP plane, as the design of the machine makes it impractical to obtain a PA image. To be consistent, all CR images for this study were also taken in the AP plane. For the purposes of this study, CR was considered the 'gold standard' for technical quality. ${ }^{16}$

In terms of technical factors, rotation evaluation was similar for both modalities, while the erect Statscan images were prone to exposure artefacts in the form of the chevron exposure artefact mentioned earlier. The erect Statscan was also prone to movement artefacts affecting the diaphragm.

The exposure artefacts were the result of rotating the C-arm of the Statscan to obtain an erect chest image. The 90-degree anti-clockwise rotation of the $\mathrm{C}$-arm used for erect views redistributes the weight of the X-ray tube, changing the centre of gravity and limiting the efficiency of the scanning motion. This results in subtle fluctuations in the scanning speed that are reflected as variations in exposure and account for the chevron exposure artefact. The longitudinally orientated dark lines represented areas of relative over-exposure corresponding to periods of slightly slower C-arm movement, while for the lighter lines, the converse applies. Lodox Systems have indicated that they have subsequently resolved this problem.

The movement artefacts were the result of the direction of scanning for the erect chest images. In the erect AP projection, scanning is from left to right (sagittal plane) whereas, for the lateral view, it is from anterior to posterior (coronal plane). In both instances, the scanning direction is perpendicular to the direction of respiratory movement of the hemidiaphragms and ribs, making the images more susceptible to changes in inspiratory or expiratory movement of the diaphragm and ribs as a result of breathing.

In our study, movement and exposure artefacts were seen in $40 \%$ and $27 \%$ of Statscan image pairs respectively. As a result, image quality was adversely affected, which influenced the diagnostic accuracy of the Statscan. These technical aspects of the Statscan erect chest views therefore compromise image quality and diagnostic accuracy and together were implicated in $93 \%$ of diagnostic errors encountered on the Statscan images.

Evaluation of the major airways revealed that the trachea and left and right main bronchi were visualised better on the Statscan than the CR images. Visualisation of the airways with the Statscan would be advantageous in developing countries with a high prevalence of pulmonary tuberculosis, given that the hallmark of paediatric PTB is enlargement of mediastinal lymph nodes, with potential for distortion of the pliable paediatric tracheo-bronchial tree. The Statscan offers a much lower radiation exposure dose compared with a 'high $\mathrm{kV}$ ' film that is generally used to delineate tracheo-bronchial narrowing. The Statscan could also be used as a screening tool in this regard if the cost is reduced.

The diagnostic capabilities for chest pathology, other than that involving the airways, appeared to be poor on the Statscan images, except for mediastinal pathology, for which Statscan and CR showed equivalent performance.

Further work is required to define the clinical role of the Statscan chest radiograph in diagnosis of proximal airway and mediastinal pathology, especially in children $<5$ years old suspected of having PTB.

It is important to note here that, in an earlier study assessing the supine Statscan AP chest projections on polytrauma patients, no movement or exposure artefacts were seen. ${ }^{11}$ For the Statscan supine AP projections, the fan-beam of ionising radiation is orientated in the axial (transverse) plane. Scanning is in a cranio-caudal direction and therefore in the same direction as respiratory movement of the hemidiaphragms and ribs, so eliminating movement artefacts. Regarding the 'chevron exposure' artefacts observed on the erect Statscan images, the most important differences between the supine and erect views appear to be due to repositioning of the C-arm. For the supine images, the C-arm is in the original position with a balanced weight distribution, optimising scanning speeds.

A supine chest image obtained with the Statscan moving in the cranio-caudal direction offers better image quality than erect chest images obtained with the Statscan. Both Statscan configurations, however, provide better visualisation of the airways than CR does.

\section{Conclusion}

The Statscan has limitations in erect chest radiography in terms of movement artefacts, exposure fluctuations, and poor definition of lung markings. Supine chest images obtained with the Statscan, however, do not show these movement and exposure artefacts. It is clear that Statscan chest images, both in the supine and erect positions, allow better visualisation of the major airways, equivalent to a 'high $\mathrm{kV}$ ' film at a fraction of the radiation dose. Statscan chest images therefore have the potential to play a role in the diagnosis of tuberculosis in children, especially in high-prevalence countries, and also in the imaging of cases where airway narrowing or compression are suspected but not clearly seen on CR images. Our hope is that the Statscan will evolve as a screening tool in suspected cases of tuberculosis.

The Lodox Statscan digital radiography machine was loaned to $\mathrm{RCH}$ for the duration of this study. None of the clinical participants or investigators has any financial interest in the company. Ethics approval from the local IRB was obtained.

1. Roebuck DJ: Risk and benefit in paediatric radiology. Pediatr Radiol 1999; 29: 637-640.

2. Mettler FA Jr, Upton AC (eds). Medical Effects of Ionizing Radiation, 2nd ed. Philadelphia: WB Saunders, 1995.

3. Legmann P. Imaging and lung disease. Tuber Lung Dis 1993 74(3): 147-158.

4. Kiljunen $\mathrm{T}$, Jarvinen $\mathrm{H}$, Savolainen $\mathrm{S}$. Diagnostic reference levels for thorax $\mathrm{X}$-ray examinations of paediatric patients. Br J Radiol 2007; 80: 452-459.

5. ICRP. Recommendations of International Commission on Radiological Protection, 60 - 1990. Ann ICRP 21: 1-201.

6. Maree GJ, Irving BJ, Hering ER. Paediatric dose measurement in a full-body digital radiography unit. Pediatr Radiol 2007; 37(10): 990-997.

7. Irving BJ, Maree GJ, Hering E, Douglas TS. Radiation dose from a linear slit scanning $\mathrm{x}$-ray machine with full body imaging capabilities. Radiat Prot Dosimetry 2008; 130(4): 482-489.

8. Douglas TS, Sanders V, Pitcher R, van As AB. Early detection of fractures with low-dose digital $\mathrm{x}$-ray images in a pediatric trauma unit. J Trauma 2008; 65(1): E4-7 


\section{ORIGINAL ARTICLE}

9. Van As AB, Douglas TS, Kilborn T, Pitcher R, Rode H. Multiple injuries diagnosed using full-body digital $\mathrm{x}$-ray. J Pediatr Surg 2006; 41(7): E25-28.

10. Koning L, Douglas TS, Pitcher R, van As AB. Short emergency department length of stay attributed to full-body digital radiography - a review of 3 paediatric cases. S Afr Med J 2006; 96(7): 613-614.

11. Pitcher $\mathrm{RD}$, van $\mathrm{As} \mathrm{AB}$, Sanders $\mathrm{V}$, et al. A pilot study evaluating the Statscan digital $\mathrm{x}$-ray machine in paediatric polytrauma. Emerg Radiol 2008; 15: 35-42.

12. Boffard KD, Goosen J, Plani F, Degiannis E, Potgieter H. The use of low dosage X-ray (Lodox/Statscan) in major trauma: comparison between low dose X-ray and conventional X-ray techniques. J Trauma 2006; 60(6): 1175-1181.
13. Jakobsson U, Westergreen A. Statistical methods for assessing agreement for ordinal data. Scand J Caring Sci 2005; 19(4): 427-431

14. Provincial Department of Health. Annual Performance Plan 2006/2007. Cape Town: Provincial Department of Health, Western Cape, 2007: 47, fig. 2.

15. Smuts NA, Beyers N, Gie R, S, et al. Value of the lateral chest radiograph in tuberculosis in children. Pediat Radiol 1994; 24: 478-480.

16. Ishigaki T, Endo $\mathrm{T}$, Ikeda $\mathrm{M}$, et al. Subtle pulmonary disease: detection with computed radiography versus conventional chest radiography. Radiology 1996; 201(1): 51-60.

\section{ERRATUM NOTICE}

The incorrect image was used in the printed version of the previous (August 2009, Vol. 13 no. 3, page 53, Fig. 4) issue of the SA Journal of Radiology. The online version was corrected shortly after its publication. The correct image is below. We apologise for the error.

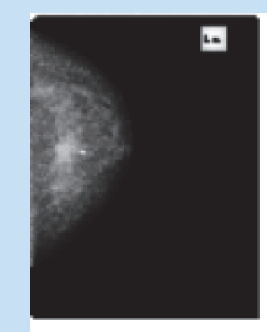

(a)

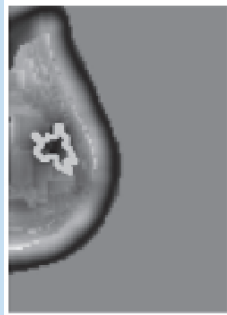

(d)

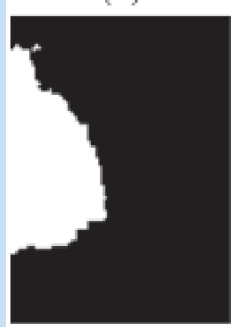

(g)

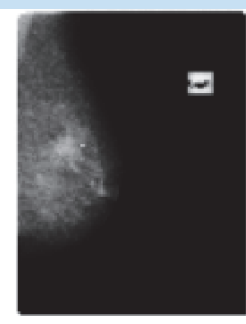

(b)

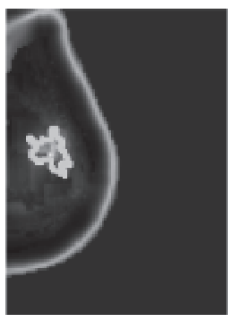

(e)

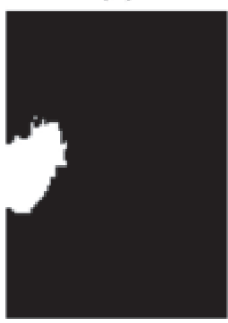

(h)

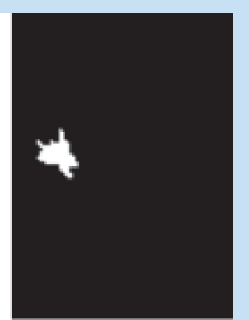

(c)

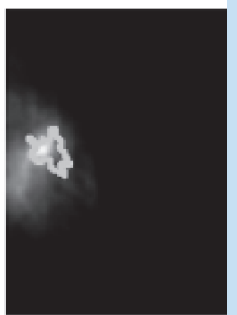

(f)

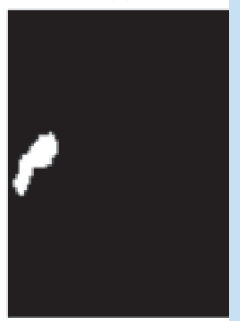

(i)

Fig. 4. Sample images: (a) reference image, (b) search image, (c) groundtruth map, (d) distance map, (e) TM similarity map, (f) MI similarity map, $(g-i)$ Ml similarity map thresholded at grey-levels of 1, 64 and 128 The thresholded maps are compared with the ground-truth map in (c) to determine the TPF- and FPF-values that were used to generate an ROC curve. 